\title{
Letters
}

\section{Planetary health needs action from health care leaders and physicians in Canada}

About 230 journals were signatories to a recently published editorial in CMAJ on the global environmental crisis. ${ }^{1}$ It served as a united voice for health care professionals calling on governments to fundamentally change the way "our societies and economies are organized." Toward the end of the editorial, the authors called for health care professionals to do "all we can to aid the transition." 1

The report from the Intergovernmental Panel on Climate Change has made it clear that we are in a "code red" situation and that action is needed within a short timeframe with respect to the climate emergency. ${ }^{2}$ We propose that every faculty of medicine create a leadership role in planetary health within the next year, as we have at the University of Ottawa, as a clear signal to faculty and learners that the climate emergency is not only important, but urgent. Using this position to advocate for longitudinal integration of planetary health into the medical school and resident curricula, to integrate sustainable health care into quality improvement initiatives, to work with medical students on community outreach, to serve as a facilitator for an interprofessional approach, and to advocate for research specifically in this area are examples of some potential actions. ${ }^{3}$

Accreditation bodies, such as the Royal College of Physicians and Surgeons of Canada, and the Association of Faculties of Medicine of Canada, need to urgently recognize knowledge about planetary health as an important educational objective. Every hospital needs to reduce its carbon footprint as part of its strategic plan. Waiting for another cycle of strategic planning to implement this reduction is suboptimal and will not allow us to meet targets. If we, as health care professionals, are uniting behind a call for governments to change fundamentally, we should look to the ethics that guide our profession. We must realize that without a healthy planet, there will be no healthy people. We need to change fundamentally too, and that change is needed now.

\section{Husein Moloo MD MPH}

Director (interim) of Planetary Health, Faculty of Medicine, University of Ottawa, Ottawa, Ont.

Cite as: CMAJ 2021 December 6;193: E1846. doi: $10.1503 / \mathrm{cmaj} .80346$

\section{References}

1. Atwoli L, Baqui AH, Benfield T, et al. Call for emergency action to limit global temperature increases, restore biodiversity, and protect health: wealthy nations must do much more, much faster. CMAJ 2021;193:E1395-7.

2. Sixth assessment report: Intergovernmental panel on climate change. Geneva: Intergovernmental Panel on Climate Change (IPCC). Available: https://www.ipcc.ch/report/ar6/wg1/ (accessed 2021 Sept. 17)

3. Seguin N, Selvam R, Moloo H. Contextually relevant healthcare professional education: why planetary health is essential in every curriculum now. J Clim Chang Health 2021;4:100044.

Competing interests: None declared.

Content licence: This is an Open Access article distributed in accordance with the terms of the Creative Commons Attribution (CC BY-NC-ND 4.0) licence, which permits use, distribution and reproduction in any medium, provided that the original publication is properly cited, the use is noncommercial (i.e., research or educational use), and no modifications or adaptations are made. See: https://creativecommons.org/ licenses/by-nc-nd/4.0/ 